\title{
RESEARCH
}

\section{A bibliometric analysis by geographic area of published research in several biomedical fields, 1995-2003}

\author{
Matthew E. Falagas, Argyris S. Michalopoulos, loannis A. Bliziotis, Elpidoforos S. Soteriades
}

\section{ABSTRACT}

We summarized the findings of several studies of ours to compare the quantity and quality of published research from around the world for the years 1995 to 2003 . We evaluated the number of articles published and their mean journal impact factor. We also studied the research productivity of various areas adjusted for gross domestic product (GDP) and population. We found that Western Europe leads the world in published research on infectious diseases-microbiology (82 342 articles [38.8\%]) and in cardiopulmonary medicine $(67783$ articles $[39.5 \%]$ ), whereas the United States ranks first in the fields of preventive medicine, public health and epidemiology both in quantity (23 918 articles [49.1\%]) and quality of published papers. However, after adjustments for GDP, Canada ranked first, with the United States and Oceania following closely behind. All of the developing regions had only small research contributions in all of the biomedical fields examined.

CMAJ 2006;175(II):1389-90

S everal investigators have conducted bibliometric analyses of research productivity of different world regions. However, comparisons between research output in different scientific disciplines are limited because of the different methodologies used. ${ }^{1-3}$ Also, not many researchers have looked at the association between potential predictors of scientific output and their interaction with geographic and population characteristics. Over the past 3 years, we have conducted a series of bibliometric analyses of several biomedical fields, including the evaluation of specific regions around the world during a 9-year period (I995-2003). ${ }^{4-11}$ In this paper, we present a comparative analysis of the research productivity of the 9 specified regions ${ }^{4-11}$ in 3 broad scientific disciplines: infectious diseases-microbiology (using the Institute for Scientific Information $^{12}$ [ISI]'s fields for infectious diseases, microbiol$\because$ ogy, virology, parasitology, tropical medicine and mycology), cardiopulmonary diseases (including the cardiac and cardiovascular systems, respiratory and critical care medicine ISI fields) and preventive medicine-public health (including the preventive, occupational and environmental medicine, public health and epidemiology ISI fields).

The methodology we used has been described in previous publications. ${ }^{4-11}$ In order to present a comparative analysis of all of the fields for the same 9-year period (1995-2003), we collected additional data for the fields of infectious diseases and cardiac and cardiovascular systems for 2003 (our published work included the periods of $1995-2002$ for the above 2 fields). The research productivity of each international region was further evaluated in relation to the population and gross domestic product (GDP) in standard 1995 US dollars, as provided by the World Bank. ${ }^{13}$

In Table I we present the scientific output from regions around the world. A large proportion of the data on the productivity of the various regions in specific research fields has already been published. ${ }^{4-11}$ When we added up the total published articles in all 3 broad scientific disciplines, multiplied by the impact factor of the individual journals in each broad category and then adjusted for the GDP of each region, Canada ranked first (total product per GDP 827), the United States ranked second (total product per GDP 639) and Oceania ranked third (total product per GDP 626).

Based on our findings, Canada had the highest research productivity (after adjusting for GDP) in most of the biomedical fields examined. Canada ranked first in the field of cardiopulmonary medicine and second in the other 2 broad categories analyzed. Also, after adding up the total product of all 3 broad categories examined and adjusting for GDP, Canada ranked first. These findings can be attributed to several factors, including the priority that has been given to research and characteristics of the academic environment in Canada. Oceania also ranked very highly in all categories when the same adjustments were made, and was closely behind the United States after adding up the total research published. Although Canada and Oceania represent positive examples of research productivity, absolute unadjusted indices may offer a different impression.

The United States leads the world in research in the fields of preventive medicine, occupational and environmental medicine, public health and epidemiology. This is not surprising, given that these areas of study have been given priority in the United States. On the other hand, researchers in Western Europe published more articles than those in the United States in the cardiopulmonary fields, as well as in 4 of the 6 infectious diseases-microbiology fields (i.e., microbiology, parasitology, tropical medicine and mycology). These findings may be explained by the long tradition of research in cardiopulmonary 
Table 1: Worldwide research productivity in several biomedical fields, 1995-2003*

No. of articles, mean impact factor, total product per population, total product per GDP†

\begin{tabular}{|c|c|c|c|c|c|c|c|c|c|c|c|c|c|c|c|c|c|c|}
\hline \multirow{2}{*}{$\frac{\text { Areał }}{\text { Canada }}$} & \multirow{2}{*}{$\begin{array}{c}\text { Population } \neq \\
31\end{array}$} & \multirow{2}{*}{$\begin{array}{c}\text { GDP } \neq \\
6.026\end{array}$} & \multicolumn{4}{|c|}{$\begin{array}{l}\text { Infectious diseases- } \\
\text { microbiology }\end{array}$} & \multicolumn{4}{|c|}{ Cardiopulmonary diseases } & \multicolumn{4}{|c|}{$\begin{array}{l}\text { Public health- } \\
\text { epidemiology }\end{array}$} & \multicolumn{4}{|c|}{ Total } \\
\hline & & & 6503 & 3.1 & 665 & 337 & 8449 & 3.1 & 853 & 432 & 1956 & 1.8 & 115 & 58 & 16908 & 3.0 & 1633 & 827 \\
\hline $\begin{array}{l}\text { United } \\
\text { States }\end{array}$ & 282 & 76.730 & 68928 & 3.5 & 855 & 315 & 63144 & 3.2 & 716 & 263 & 23918 & 2.0 & 166 & 61 & 155990 & 3.1 & 1737 & 639 \\
\hline Oceania & 30 & 4.674 & 6273 & 2.7 & 548 & 358 & 3929 & 2.7 & 345 & 225 & 1194 & 1.8 & 69 & 45 & 11396 & 2.6 & 962 & 626 \\
\hline $\begin{array}{l}\text { Western } \\
\text { Europe }\end{array}$ & 389 & 89.804 & 82342 & 2.8 & 595 & 257 & 67783 & 2.5 & 441 & 191 & 15740 & 1.5 & 61 & 27 & 165865 & 2.6 & 1097 & 475 \\
\hline Africa & 779 & 4.888 & 6126 & 1.8 & 14 & 226 & 877 & 1.8 & 2 & 33 & 571 & 1.5 & 1 & 18 & 7574 & 1.8 & 17 & 276 \\
\hline $\begin{array}{l}\text { Eastern } \\
\text { Europe }\end{array}$ & 421 & 9.862 & 5146 & 1.7 & 21 & 88 & 4082 & 1.4 & 14 & 59 & 771 & 1.2 & 2 & 9 & 9999 & 1.5 & 37 & 156 \\
\hline Asia & 3387 & 32.086 & 13535 & 2.1 & 8 & 88 & 7629 & 2.1 & 5 & 49 & 2452 & 1.4 & 1 & 10 & 23616 & 2.0 & 14 & +147 \\
\hline Japan & 127 & 50.423 & 13234 & 2.3 & 244 & 61 & 13783 & 2.7 & 292 & 73 & 1393 & 1.3 & 14 & 4 & 28410 & 2.5 & 550 & 138 \\
\hline $\begin{array}{l}\text { Latin } \\
\text { America }\end{array}$ & 504 & 16.751 & 10332 & 1.7 & 34 & 102 & 1880 & 2.3 & 9 & 26 & 686 & 1.7 & 2 & 7 & 12898 & 1.8 & 45 & 136 \\
\hline Total & 5950 & 291.244 & 212419 & 2.9 & 102 & 208 & 171556 & 2.8 & 80 & 163 & 48681 & 1.7 & 14.2 & 29 & 432656 & 2.7 & 196 & 399 \\
\hline
\end{tabular}

Note: GDP = gross domestic product.

*The analysis includes articles published (1995-2003) in journals indexed by the Institute for Scientific Information in the fields of infectious diseases-microbiology (infectious diseases, microbiology, virology, parasitology, tropical medicine and mycology), cardiopulmonary diseases (cardiac and cardiovascular systems, respiratory medicine and critical care medicine) and public health-epidemiology (preventive, occupational and environmental medicine, public health and epidemiology).

†Total product is defined as the sum of the number of articles published multiplied by the impact factor of the individual journals of each broad category. The average population and total GDP (in 1995 US dollars) of the world areas examined during the study period were used in the analysis..$^{5,7}$ Total product per population and total product per GDP of the various areas refer to number of articles multiplied by journal impact factor per million people and per ten trillions of 1995 US dollars, respectively.

†The geographic areas were ranked in descending order based on their total research product (in the 3 broad categories analyzed) adjusted for GDP (last column of the table). Latin America includes the Caribbean. Asia does not include Japan, for which there are separate data. The average population of the geographic areas during the study period is presented in millions. GDP is the total GDP of each area for the study period (in trillions of 1995 US dollars).

medicine and infectious diseases-microbiology in Europe. Unfortunately, the developing regions of the world contribute a very small amount of research to the worldwide biomedical research output. What is even more worrisome is that developing countries are low on the list of research productivity even after adjusting for GDP. Our analysis does have limitations in the interpretation of all of the results, as described in our original bibliometric papers. ${ }^{4-11,14}$

In summary, the fact that the scientific production of researchers in Canada is higher (when adjusted for GDP) compared with other regions around the world deserves careful attention by the worldwide scientific community, as well as by public and private funding organizations, to identify the key determinants contributing to the cost-effective research productivity of this country.

This article has been peer reviewed.

From the Alfa Institute of Biomedical Sciences (Falagas, Michalopoulos, Bliziotis, Soteriades), and the Department of Medicine (Falagas) and the Intensive Care Unit (Michalopoulos), Henry Dunant Hospital, Athens, Greece, and the Department of Medicine, Tufts University School of Medicine (Falagas), and the Department of Environmental Health, Occupational Health Program, Harvard School of Public Health (Soteriades), Boston, Mass.

\section{Competing interests: None declared.}

Contributors: Matthew Falagas conceived of the idea for the analysis and developed the methodology used with Ioannis Bliziotis and Elpidoforos Soteriades. Ioannis Bliziotis collected the data for the review. All of the authors contributed to the analysis and interpretation of the data and the writing of the manuscript and approved the final version.

\section{REFERENCES}

I. Jemec GB. Impact factors of dermatological journals for I99I-2000. BMC Dermatol 200I; I:7.

2. Rahman M, Fukui T. Biomedical publication-global profile and trend. Public Health 2003;117:274-80.

3. Mela GS, Martinoli C, Poggi E, et al. Radiological research in Europe: a bibliometric study. Eur Radiol 2003;13:657-62

4. Vergidis PI, Karavasiou AI, Paraschakis K, et al. A bibliometric analysis of global trends of research productivity in microbiology. Eur J Clin Microbiol Infect Dis 2005;24:342-6.

5. Bliziotis IA, Paraschakis K, Vergidis PI, et al. Worldwide trends in quantity and quality of published articles in the field of infectious diseases. BMC Infect Dis 2005;5:16.

6. Rosmarakis ES, Vergidis PI, Soteriades ES, et al. Estimates of global production in cardiovascular diseases research. Int J Cardiol 2005;100:443-9.

7. Falagas ME, Karavasiou AI, Bliziotis IA. Estimates of global research productivity in virology. J Med Virol 2005;76:229-33.

8. Michalopoulos AS, Bliziotis IA, Rizos M, et al. Worldwide research productivity in critical care medicine. Critical Care 2005;9:R258-65. Available: http://ccforum .com/content/pdf/cc35I4.pdf (accessed 2006 Sept 22).

9. Falagas ME, Papastamataki PA, Bliziotis IA. A bibliometric analysis of research productivity in parasitology by different world regions during a 9-year period (1995-2003). BMC Infect Dis 2006;6:56.

Io. Michalopoulos A, Falagas ME. A bibliometric analysis of global research production in respiratory medicine. Chest 2005;128:3993-8.

II. Falagas ME, Karavasiou AI, Bliziotis IA. A bibliometric analysis of global trends of research productivity in tropical medicine. Acta Trop 2006 Sept 30; [Epub ahead of print].

I2. Institute for Scientific Information. SCI: Science Citation Index-Journal Citation Reports. Philadelphia: The Institute for Scientific Information; 2004.

I3. World Bank Group. World development indicators online. Available: http://devdata .worldbank.org/data-query/ (accessed 2006 Sept 22).

I4. Seglen PO. Why the impact factor of journals should not be used for evaluating research. BMJ I997;314:498-502.

Correspondence to: Dr. Matthew E. Falagas, Alfa Institute of Biomedical Sciences, 9 Neapoleos St., I5I 23 Marousi, Athens, Greece; fax+30 210683-9605; m.falagas@aibs.gr 